\title{
Health Related Quality of Life and Associated Factors Among HIV Patient on Highly Active Antiretroviral Therapy at Assosa Hospital, Northwest Ethiopia, 2019
}

\author{
Paulos Jaleta Wondasho ${ }^{1}$, Mulugeta Adimasu ${ }^{2}$ \\ ${ }^{1}$ Department of Nursing, Health Science College, Assosa University, Assosa, Ethiopia \\ ${ }^{2}$ Department of Public Health, Health Science College, Assosa University, Assosa, Ethiopia \\ Email address: \\ paulosjaleta123@gmail.com (P. J. Wondasho), mulugetaadmsau@gmail.com (M. Adimasu) \\ To cite this article: \\ Paulos Jaleta Wondasho, Mulugeta Adimasu. Health Related Quality of Life and Associated Factors Among HIV Patient on Highly Active \\ Antiretroviral Therapy at Assosa Hospital, Northwest Ethiopia, 2019. American Journal of Clinical and Experimental Medicine. \\ Vol. 9, No. 4, 2021, pp. 102-108. doi: 10.11648/j.ajcem.20210904.13
}

Received: June 30, 2021; Accepted: July 15, 2021; Published: July 23, 2021

\begin{abstract}
Health-related quality of life is a broad concept reflecting a patient's general subjective perception of the impact an illness and treatment given for them. It measures an integral part of patient follow up by providing valuable feedback about the disease as well as associated interventions. The aim of this study was to assess health related quality of life and associated factors among HIV patient on highly active antiretroviral therapy at Assossa general hospital. Institution based cross-sectional study design was conducted among HIV positive patient from February, 8 to March, $21^{\text {st }} 2018$ at Assossa general hospital. Data was collected using medical outcome study HIV questionnaire, systematic sampling technique was used, entered in to Epi-info software version 7 analyzed using the statistical product and service solution version 20 . Bivariate at $p$-value $<0.2$ and Multivariate Logistic regression p-value at $<0.05$ was used to identify factors associated with health related quality of life. Three hundred participants with $96.5 \%$ response rate were involved in the study. About fifty six point seven percent of the study participants mean $( \pm \mathrm{SD})$ score of overall health related quality of life was $54.85 \pm 11.3$. Participant that had viral load copies of forty and below were $\mathrm{AOR}=3.19(95 \% \mathrm{CI} 1.73,5.91)$ associated with good health related quality of life and participant who have no recent opportunistic infection were $\mathrm{AOR}=2.87(95 \% \mathrm{CI} 1.49,5.51)$ associated with good health related quality of life. Therefore, the health related quality of life was good. Occupational status, living condition viral load copies $/ \mathrm{ml}$ and opportunistic infection showed association with good health related quality of life and Further research was suggested.
\end{abstract}

Keywords: Acquired Immunodeficiency Syndrome, Health Related Quality of Life, Opportunistic Infection

\section{Introduction}

Human immunodeficiency virus (HIV) is the virus that attacks white blood cells that are crucial to the normal functioning of the immune system and which protects the body against illness. Whereas Acquired Immunodeficiency Syndrome (AIDS) which occurs when the immune system is weakened by HIV to the point where a person is susceptible to any number of Opportunistic Infections (OIs) or diseases [1].

HIV/AIDS pandemic remains the most serious of infectious disease challenges to public health but following the emergency of highly active antiretroviral therapy (HAART) changed the disease's natural course, marking a considerable reduction in mortality, the occurrence of opportunistic infections, the time of hospitalization, and the time interval until progression to AIDS [2]. Current HAART formulation are now more effective, easier to take, and often better tolerated than the first HAART regimens. Still, patients are burdened with having to take lifetime treatment with potential adverse effects, which may diminish their healthrelated quality of life (HRQoL) [3].

As of World Health Organization (WHO), "Quality of life is defined as an individuals' perception of their position in life in the context of the culture and value systems in which they live in relation to their goals, expectations, standards and concerns". This indicates individuals satisfaction depends on their physical, mental, social relationships, cognitive and spiritual aspects of their life $[4,5]$. Nearly 36.7 million people 
had HIV infections across the world in 2016, compared to 33.3 million in 2010 and HIV prevalence was estimated to be $0.8 \%$ in 2016 that has leveled with the prevalence reported in 2001 and the vast majority of people living with HIV were found in low- and middle-income countries [6].

The introduction of highly active antiretroviral therapy has reduced global HIV/AIDS-related deaths from 1.5million in 2010 to 1.1 million in 2016. Beside this, sustained viral suppression and reduction of viral load in the blood and other bodily fluids has led to substantial decreases in the incidence of AIDS-defining illness and AIDS-related morbidity and mortality $[7,8]$.

Ethiopia is one of the sub-Saharan African countries severely heated by the HIV/AIDS pandemic and HIV has penetrated even the hard-to-reach rural areas. However, with the existing socio-cultural diversity of the country, the prevalence and distribution of HIV greatly varies by region, place of residence and sex of individuals [9]. Prevalence rate of HIV was estimated to be $1.16 \%$ and 14,872 death 22,827 newly infected with HIV in the country [10].

Survival among patients infected with HIV has significantly improved following the introduction highly active antiretroviral therapy. But still, patients are burdened with taking lifetime treatment and drug adverse effects, which may diminish their health-related quality of life. These judgments include the expectations learnt from experiences, highly specific and vary between individuals in physical mental, economic and employment status are factors influencing quality of life based on previous studies on quality of life in relation to education and employment $[11,12]$.

Measuring HRQoL can give base line data for health care managers and authorities or policy maker, NGO, researchers and health care worker as it make possible for evaluation of the efficiency, effectiveness and cost-benefit ratio of health care programmes, and for pharmaceutical companies that gather data on effectiveness, clinical benefit, satisfaction with treatment and treatment adherence of HIV patients. HRQoL assessment will also help clinicians and policy maker to make judgments about areas of need of PLWHA and will be assistance in planning the interventions to address these needs with the overall aim of improving quality of life. Therefore this study will be designed to assess how PLWHA who accessed care are perceived their health related quality of life from ART clinic at Assossa Hospital.

\section{Methods and Materials}

\subsection{Study Design}

Institution based cross-sectional study was conducted.

\subsection{Study Area and Period}

Assossa general hospital is found in capital city of Benishangul Gumuz regional state Assossa town that serves total population of around 261449. There for, the study was conducted in Assossa general hospital with the total number of PLWHA currently enrolled in chronic care were found to be around $1127[13,14]$ and the study was conducted from February 8, to march 21, 2018.

\subsection{Source Population}

All HIV positive patient who were on Highly Active Antiretroviral Therapy at Assosa general hospital.

\subsection{Study Population}

All HIV positive patient who were on Active Antiretroviral Therapy that fulfill the inclusion criteria and available during the study period.

\subsection{Inclusion Criteria}

1) All HIV positive patients on ART who were age $>18$ years.

2) Known HIV positive patient enrolled in chronic care for at least six (6) months and above.

\subsection{Sample Size}

It was calculated by using single population proportion formula with Epi Info-7 software to obtain required sample size with the following assumption. proportional rate $43.6 \%$ [15] and $10 \%$ non-response rate. Based on this assumption Single population proportional formula was used to describe as follows:

The final sample size by adding $10 \%$ (28) nonresponsive rate was $283+28=311$.

\subsection{Dependent Variable}

\subsubsection{Health Related Quality of Life Study Subject}

HRQoL dimension includes (General Health perception, Vitality, Bodily pain, Quality of life, Health distress, Role functioning, Cognitive functioning, Social functioning, Physical functioning, Health transition).

\subsubsection{Independent Variables}

The selected Sociodemographic variables were (Age, Gender, Family size, Education status, Occupational status marital status, Living condition, Residence, Income, Religion, and Social Support).

\subsubsection{Clinical Factors}

The selected clinical characteristic variable were (Duration of treatment, WHO Clinical stage, recent viral load, recent CD4+count, Adherence status, HAART Regimen, Functional status, opportunistic infection).

\subsubsection{Behavioral Factors}

The selected behavioral characteristic of the study participant were (Alcohol, Chat, cigarette smoking and illicit drug use).

\subsection{Operational Definition}

Good health related quality of life is means study subject those who score above the mean from 11 dimension of MOS HIV questionnaire [16-19].

Poor health related quality of life those who score below the mean was taken after summarizing and computing 11dimension of MOS HIV questionnaire [16, 18-20]. 


\subsection{Data Quality Assurance}

Data was checked for its completeness and missing items in every moment. Beside all this data was checked for completeness during data collection, entry and compilation before analysis was made by principal investigator. Furthermore, translation of the English version questionnaire into Amharic language was carried out. by Amharic speakers English language professionals and data was cleaned before analysis carried on.

\subsection{Data Analysis}

Data was entered into Epi info version 7software. and exported to SPSS version 20. Data was presented with frequency tables. bivariate analysis was used with cut of point at $\mathrm{P}<0.2$ and entered into multivariable analysis then significance level was sated at $\mathrm{P}<0.05$ and confidence level of $95 \%$. By considering mean of each dimension HRQoL was categorized as poor or good HRQoL. score below the mean classified poor quality of life for 11 domains. Finally, model fitness was checked using Hosmer and Lemeshow statistical fit test.

\subsection{Ethical Clearance}

This was obtained from ethical review committee of Debre Markose University college of Health science. After that study subject were oriented about the purpose, procedure of data collection, confidentiality, privacy and the absence of any direct benefit. participation was based on willingness using written and verbal consent and who were unwilling to participate and refusing the consent were respected. Cited references were presented for due acknowledgement of academic source.

\section{Result}

\subsection{Socio-demographic Characteristics}

A total of $311 \mathrm{HIV}$ positive patient were sampled for this study. From this three hundred $(96.5 \%)$ were responded with the mean age of the study participants was found to be (37 \pm SD 9.57) years. Out of the total participants $155(51.7 \%)$ were female and $142(47.3 \%)$ were married currently and living together. Concerning the religious categories of the study participants, $158(52.7 \%)$ orthodox, 96 (32.0\%) Muslim and $43(14.3 \%)$ were catholic faith follower. Regarding family size, occupational status and monthly income of the study participants $164(54.7 \%)$ had three and more than three family member, 205 (68.5\%) were employed and $70(23.3 \%)$ of the study participants had below 500 Ethiopia birr and 111 (37\%) had monthly income of 2000 thousand Ethiopian birr and above respectively. Concerning social support $214(71.3 \%)$ had support from family or their friends the remaining finding of this study were displayed below in (table 1).

Table 1. Distribution of Socio-demographic characteristic of HIV positive patient at Assossa General Hospital Benishangule Gumuze Regional State, West Ethiopia 2018.

\begin{tabular}{|c|c|c|c|}
\hline Variable & Category & Frequency $(n=300)$ & Percent (\%) \\
\hline \multirow{2}{*}{ Age } & $18-35$ & 137 & 45.7 \\
\hline & $>35$ & 163 & 54.3 \\
\hline \multirow{2}{*}{ Sex } & Male & 145 & 48.3 \\
\hline & Female & 155 & 51.7 \\
\hline \multirow{3}{*}{ Religion } & Orthodox & 158 & 52.7 \\
\hline & Muslim & 96 & 32 \\
\hline & Catholic & 43 & 14.3 \\
\hline \multirow{2}{*}{ Place of living } & Urban & 233 & 77.7 \\
\hline & Rural & 67 & 22.3 \\
\hline \multirow{2}{*}{ Family size } & $<=2$ & 136 & 45.3 \\
\hline & $>=3$ & 164 & 54.7 \\
\hline \multirow{3}{*}{ Marital status } & Single & 48 & 16 \\
\hline & Married & 142 & 47.3 \\
\hline & Divorced & 68 & 22.7 \\
\hline \multirow{2}{*}{ Occupational status } & Employed & 205 & 68.3 \\
\hline & Unemployed & 95 & 31.7 \\
\hline \multirow{5}{*}{ Monthly income } & $<500$ & 70 & 23.3 \\
\hline & $501-999$ & 33 & 11 \\
\hline & $1000-1499$ & 55 & 18.3 \\
\hline & $1500-1999$ & 31 & 10.3 \\
\hline & $>=2000$ & 111 & 37 \\
\hline \multirow{4}{*}{ Level of education } & Illiterate & 70 & 23.3 \\
\hline & Primary school & 78 & 26 \\
\hline & Secondary school & 64 & 21.3 \\
\hline & Higher education & 88 & 29.3 \\
\hline \multirow{2}{*}{ Living condition } & Alone & 81 & 27 \\
\hline & With family/friends & 219 & 73 \\
\hline \multirow{2}{*}{ Social support } & No & 86 & 28.7 \\
\hline & Yes & 214 & 71.3 \\
\hline
\end{tabular}




\subsection{Clinical Characteristics}

All of the clinical data available on patient chart were updated after initial entry to the time of data collection. Out of all the study participant $210(70 \%)$ individual had taken treatment for more than three years and the dominant WHO clinical stages at the time of this study were stage one 201 $(67 \%)$ and stage three $53(17.7 \%)$ respectively. Concerning recent viral load 174 (58\%) of the study participant had more than 40 copies $/ \mathrm{ml}$ and around $119(39.7 \%)$ participant had opportunistic infection (table 2).

Table 2. Clinical characteristics of patient on HAART at Assossa General Hospital Benishangul Gumuz Regional State west Ethiopia, 2018.

\begin{tabular}{llll}
\hline Variable & Category & Frequency $(\mathbf{n}=\mathbf{3 0 0})$ & Percent\% \\
\hline Duration of treatment & $<=36$ & 90 & 30 \\
(in months) & $>36$ & 210 & 70 \\
RecentCD4+ cells & $<=350$ & 143 & 47.7 \\
count/mm ${ }^{3}$ & $>350$ & 157 & 52.3 \\
Recent Viral load & $<=40$ & 148 & 49.3 \\
& $>40$ & 152 & 50.7 \\
Recent WHO Clinical & Stage I & 201 & 67 \\
Stage & Stage II & 8 & 2.7 \\
& Stage III & 53 & 17.7 \\
HAART Regimen & Stage IV & 38 & 12.3 \\
& First line & 231 & 77 \\
Adherence status & Second line & 69 & 23 \\
& Good & 227 & 73.7 \\
& Fair & 62 & 20.7 \\
Functional status & Poor & 17 & 5.7 \\
& Working & 243 & 81 \\
Opportunistic & Ambulatory & 49 & 16.3 \\
infection & Bedridden & 8 & 2.7 \\
\hline & No & 181 & 60.3 \\
\hline
\end{tabular}

\subsection{Behavioral Characteristics}

From the total three hundred eleven sample size three hundred were responded for the interview with $96.7 \%$ response rate. Out of the total study participants who reported Chewing chat accounts 95 (31.7\%), drinking alcohol 92 $(30.7 \%)$, Illicit drug use were $64(21.3 \%)$ and cigarette smoker were 93 (31\%) at the time of data collection (table 3).

Table 3. The Distribution of Behavioral characteristics of HIV positive patient at Assossa General Hospital Benishangul Gumuz Regional State, West Ethiopia April, 2018

\begin{tabular}{llll}
\hline Variable & Category & Frequency $(\mathbf{n = 3 0 0})$ & Percent (\%) \\
\hline \multirow{2}{*}{ Chewing chat } & No & 205 & 68.3 \\
& Yes & 95 & 31.7 \\
Alcohol & No & 208 & 69.3 \\
drinking & Yes & 92 & 30.7 \\
Cigarette & No, & 207 & 69 \\
smoking & Yes & 93 & 31 \\
\multirow{2}{*}{ Illicit drug use } & No, & 236 & 78.7 \\
& Yes & 64 & 21.3 \\
\hline
\end{tabular}

\subsection{Health Related Quality of Life of Study Subject}

About 300 participants completed the MOS-HIV Health Survey questionnaire and out of this $48 \%$ had good general health perception, around 167 (55.7\%) the study participant had good physical health, and around one hundred sixty one (53.7\%) of the study participant had good cognitive functioning. More than half 158 (52.7\%) participants had good MHS. The overall HRQoL mean score of the study participant was $54.85 \pm 11.3$ and fifty six point seven percent of participant have good health related quality of life. The transformed mean scores of each of the 11 MOS-HIV dimension and two summary scores were presented below (table 4).

Table 4. Medical outcome study HIV dimension score of 300 study participants who were on HAART at Assossa General Hospital Benishangul Gumuz Regional State west Ethiopia 2018.

\begin{tabular}{llll}
\hline Dimension & $\begin{array}{l}\text { Range } \\
\text { of raw } \\
\text { score }\end{array}$ & $\begin{array}{l}\text { Transformed } \\
\text { mean score } \pm\end{array}$ & $\begin{array}{l}\text { Respondents that } \\
\text { Score above mean } \\
\text { in (\%) }\end{array}$ \\
\hline $\begin{array}{l}\text { General Health } \\
\text { perception }\end{array}$ & $5-25$ & $49.1 \pm 1.9$ & $144(48 \%)$ \\
Physical health & $6-18$ & $63.91 \pm 4.75$ & $167(55.7 \%)$ \\
Bodily pain & $2-11$ & $43.1 \pm 4.2$ & $130(43.3 \%)$ \\
Vitality/fatigue & $4-24$ & $51.05 \pm 3.8$ & $39(13 \%)$ \\
Social function & $1-6$ & $45.6 \pm 2.3$ & $138(46 \%)$ \\
Role function & $2-4$ & $45 \pm .98$ & $137(45.7 \%)$ \\
Mental health & $5-30$ & $48.3 \pm 3.0$ & $168(56 \%)$ \\
Health distress & $4-24$ & $60 \pm 9.1$ & $177(59 \%)$ \\
Cognitive function & $4-24$ & $55.6 \pm 9.11$ & $161(53.7 \%)$ \\
Quality of life & $1-5$ & $42.75 \pm 1.91$ & $128(42.7 \%)$ \\
Health transition & $1-5$ & $42.75 \pm 1.91$ & $129(42.7 \%)$ \\
Physical summary score & - & $54.8 \pm 5.7$ & $160(53.3 \%)$ \\
Mental summary score & - & $54.9 \pm 16.8$ & $158(52.7 \%)$ \\
Over all HRQoL & - & $54.85 \pm 11.3$ & $170(56.7 \%)$
\end{tabular}

\subsection{Factors Associated with Health Related Quality of Life}

All questionnaire were summarized and computed then over all health related quality of life were generated. Then logistic regression analysis shows that variables like place of living (residence), level of education, occupational status, social support from family/friends, living condition, recent viral load, functional status, illicit drug use, HAART regimen, opportunistic infection, illicit drug use, alcohol drink, shows association in bivariate regression model at $\mathrm{p}<0.2$.

In multivariable logistic regression model only living condition, absence of opportunistic infection and decreased number of viral load shows significant association with good overall health related quality of life at $p<0.05$. This study revealed that participants who were employed found to be $\mathrm{AOR}=2.2(95 \% \mathrm{CI}=1.29,3.73)$ times more likely to good health related quality of life as compared with their counterpart. The study participants who were living with their family and friends $\mathrm{AOR}=1.49(95 \% \mathrm{CI} 1.14,3.34)$ time more likely to have good health related quality of life than those who were living alone and participants that had viral load copies of forty and below were $\mathrm{AOR}=3.19(95 \% \mathrm{CI}, 1.73,5.91)$ times more likely to have good health related quality of life as compared to their counterpart. participant who has no recent opportunistic infection were $\mathrm{AOR}=2.87$ (95\% CI, 1.49, 5.51) times more likely to have good health related quality of life as compared to those who had opportunistic infection (table 5). 
Table 5. Bivariate and multivariable logistic regression result of Factors associated with health related quality of life of HIV positive patients at Assossa general hospital in Benishangul Gumuz regional state West Ethiopia, 2018 (n=300).

\begin{tabular}{|c|c|c|c|c|c|c|}
\hline \multirow{2}{*}{ Variables } & \multirow{2}{*}{ Category } & \multicolumn{2}{|l|}{ HRQoL } & \multirow{2}{*}{ COR $(95 \%$ CI $)$} & \multirow{2}{*}{ AOR $(95 \%$ CI) } & \multirow{2}{*}{ p-value } \\
\hline & & Good & Poor & & & \\
\hline \multirow{2}{*}{ Living condition } & With family & $136(45.33 \%)$ & $83(27.66 \%)$ & $2.26(1.35,3.81)$ & $1.95(1.14,3.34)^{*}$ & \multirow[t]{2}{*}{0.014} \\
\hline & Alone & 34 (11.33\%) & $47(15.66 \%)$ & 1.00 & 1.00 & \\
\hline \multirow{2}{*}{$\begin{array}{l}\text { Occupational } \\
\text { status }\end{array}$} & Employed & $129(43 \%)$ & $76(25.33 \%)$ & $2.23(1.36,3.66)$ & $2.20(1.29,3.73)^{*}$ & \multirow[t]{2}{*}{0.004} \\
\hline & Unemployed & $41(13.66 \%)$ & $54(18 \%)$ & 1.00 & 1.00 & \\
\hline \multirow{2}{*}{ Chat chew } & No & $130(43.33 \%)$ & $84(28 \%)$ & $1.78(1.07,2.95)$ & $1.99(0.66,6.02)$ & \multirow[t]{2}{*}{0.22} \\
\hline & Yes & $40(13.33 \%)$ & $46(15.33 \%)$ & 1.00 & 1.00 & \\
\hline \multirow{2}{*}{$\begin{array}{l}\text { Cigarette } \\
\text { smoking }\end{array}$} & No & $137(45.66 \%)$ & $70(23.33 \%)$ & $3.56(2.13,5.95)$ & $0.72(0.23,2.23)$ & \multirow[t]{2}{*}{0.57} \\
\hline & Yes & $33(11 \%)$ & $60(20 \%)$ & 1.00 & 1.00 & \\
\hline \multirow{2}{*}{ Alcohol drink } & No & $140(46.66 \%)$ & $68(22.66 \%)$ & $4.25(2.52,7.18)$ & $0.99(0.28,3.32)$ & \multirow[t]{2}{*}{0.99} \\
\hline & Yes & $30(10 \%)$ & $62(20.66 \%)$ & 1.00 & 1.00 & \\
\hline \multirow{2}{*}{ HAART regimen } & First line & $150(30 \%)$ & $81(27 \%)$ & $4.53(2.25,8.15)$ & $1.49(0.63,3.54)$ & \multirow[t]{2}{*}{0.37} \\
\hline & Second line & $20(6.66 \%)$ & $49(16.33 \%)$ & 1.00 & 1.00 & \\
\hline \multirow{2}{*}{$\begin{array}{l}\text { Opportunistic } \\
\text { infection }\end{array}$} & No & $141(47 \%)$ & $54(18 \%)$ & $6.84(4.03,11.63)$ & $2.87(1.49,5.51)^{*}$ & \multirow[t]{2}{*}{0.017} \\
\hline & Yes & $29(9.66 \%)$ & $76(25.33 \%)$ & 1.00 & 1.00 & \\
\hline \multirow{2}{*}{ Recent Viral load } & $<=40$ & $100(33.33 \%)$ & $26(8.66 \%)$ & $5.71(3.37,9.68)$ & $3.19(1.73,5.91)^{*}$ & \multirow[t]{2}{*}{0.001} \\
\hline & $>40$ & $70(23.33 \%)$ & $104(34.66 \%)$ & 1.00 & 1.00 & \\
\hline
\end{tabular}

Table 6. Factors associated with health related quality of life of HIV positive patients at Assossa general hospital in Benishangul Gumuz regional state West Ethiopia, $2018(n=300)$.

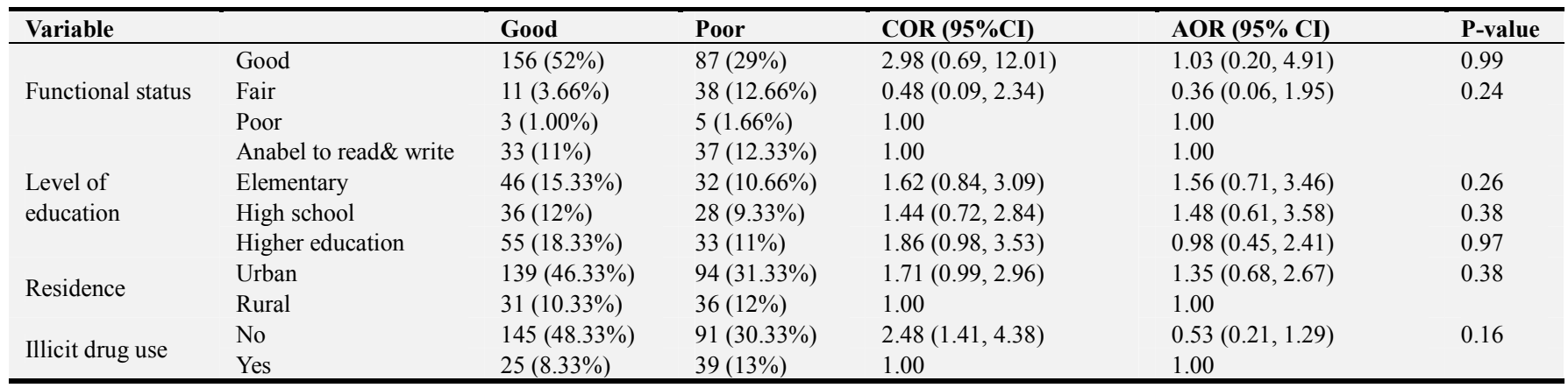

$\mathrm{NB}$ : * indicate statistical significance level at $\mathrm{p}$-value $<0.05$

\section{Discussion}

The present study intended to assess health related quality of life and associated factors among PLWHA at Assossa general hospital. In this paper, the participants mean $( \pm \mathrm{SD})$ score of physical health (63.91), mental health (48.3), cognitive function (55.7) and energy/fatigue (51.01) were found to be comparable with study which was conducted in Iran [19]. But it was lower as compared to study done in Ireland, Greek and Uganda [2, 16, 21]. This variation might be because of methodological difference, study area and due to the fact that health related quality of life is socio demographically sensitive.

Overall mean score of HRQoL in our study area was $54.85 \pm 11.3$ which is comparable with the study done in Ireland and Iran $[16,19]$. Moreover, the transformed mean score for physical health summary and mental health summary score were $54.8 \pm 5.7$ and 54.9 \pm 16.8 , respectively which was consistent with studies conducted in other countries, including Ireland, Belgium and Iran $[16,22,23]$. On the other hand, HRQoL study participants reported in this paper higher was compared to study done at Bahirdar [15]. This variation might be due to difference in data collection tools and improved HIV care service in the country following up to dated training which was given in the year 2014 for all health care worker who are providing HIV care and treatment service in ART clinic and the effectiveness of some of the interventions for HIV positive patient who were exposed to ART clinic.

Conferring to this study participants that had viral load copies of forty and below were AOR $=3.19(95 \% \mathrm{CI}, 1.73,5.91)$ times more likely to have good HRQoL. Even if many of previous study did not show its association with HRQoL; this finding was comparable with study done at Thailand and Portugal, decreased virological status was associated with a good HRQoL [18, 24, 25]. The possible justification might be its relationship with immunological Status because as viral load decreases there might be improvement in CD4-cell count and decreased vulnerability to disease that finally leads to improvement in HRQoL corroborated by scientific evidence.

This Study shows that Participants who have no recent OI were $\mathrm{AOR}=2.87(95 \% \mathrm{CI}, 1.49,5.51)$ times more likely to have good HRQoL as likeness to those who had opportunistic infection. This finding was comparable with study done Valladolid a tertiary hospital RioHortega University and Uganda [21, 26]. The possible justification might be due to 
the fact that the presence of opportunistic infection will have moderate to severe body function alteration due to the nature of disease process that finally affects HRQoL of HIV positive people who are on HAART. The presence of opportunistic infection cause individual to have compromised daily living activities, limited participation income generating activities and finally affect health related quality of life.

The subject who were currently living with their family or friends found to be $\mathrm{AOR}=1.95(95 \% \mathrm{CI}, 1.14,3.34)$ times good health related quality of life as likeness to those who were living alone. This finding was comparable with study done in Cambodia and Iran [19, 27]. The possible justification might be those who were living with their family or friend might have good or better social support that had indirect role in HRQoL, by mediating depression. In fact, biological treatments were not enough for treating such patients and, at the same time, getting familiar with and eliminating their mental problems can be a good prognosis for their treatment. This finding suggests that, improving social support could reduce depressive symptoms, which then could improve HRQoL.

This study revealed Employed Participants were AOR=2.2 (95\% CI, 1.29, 3.73) times to have good health related quality of life as compared with those who were not employed. This study demonstrates the same finding with similar study conducted in Bangladesh, Canada, Ethiopia and Zimbabwe [15, 22-29]. The possible justification might be due to the fact that being unemployed have negative impact on psychological well-being and HRQoL of individual due to feeling of worthlessness, loneliness, financial limitations that could result poor standard of living condition. People with HIV may be disinclined to go back to work or seek new job because of the stress and misconceptions related to disclosure of their HIV status to their employers and colleagues which results in poor HRQoL.

\section{Conclusions}

This study showed that HRQoL of study participants was good. Living condition, occupational status, viral load copies/ml and opportunistic infection revealed significant association with good health related quality of life. On the other hand, age, sex, family size, income level of education was not associated with health related quality of life.

\section{Limitation}

1) Participants for this study were recruited from one urban hospital so; this could limit the generalizability of the findings to other facility. Inferring this finding to other settings would be with great caution due to the fact that HRQoL is highly sensitive to socio-cultural and demographic nature of the HIV positive people.

2) The nature of study design limit us not to assess change in HRQoL over time. Making follow up for study subject might provide valuable information on changes in HRQoL.

\section{Acknowledgements}

I wish to express my sincerest and warmest gratitude to my advisor Mr, Getachew Mullu. He has been guiding, providing valuable advice and unreserved support throughout thesis work.

I would like to express my gratitude to Abebe Dilie for his unreserved support.

I am grateful to thank Debre Markos University and Benishangul-Gumuz Regional State Health Bureau for giving me the chance for study. Assossa hospital for their impressive cooperation in provision of baseline data for this research proposal work and during the time of data collection.

Gratefulness to all the study participants for devoting much of their invaluable time during the interview.

All data collectors and supervisor were very much appreciated for their patience and strength during the time of data collection.

Lastly but not least I also thank those whom I might have overlooked to cite, but contributed to the thesis work in one way or the other.

\section{References}

[1] Bradley H, Hall H, Wolitski R, Van Handel M, Stone A, LaFlam M, et al. Vital Signs: HIV diagnosis, care, and treatment among persons living with HIV--United States, 2011. MMWR Morbidity and mortality weekly report. 2014; 63 (47): 1113-7.

[2] Stasinopoulou PG, Tzavara C, Dimitrakaki C, Georgiou O, Baraboutis IG, Skoutelis A, et al. Reliability and validity of the Greek translation of the MOS-HIV health survey in HIVinfected individuals. Quality of Life Research. 2010; 19 (2): 199-205.

[3] de Boer-van der Kolk IM, Sprangers MA, Prins JM, Smit C, de Wolf F, Nieuwkerk PT. Health-related quality of life and survival among HIV-infected patients receiving highly active antiretroviral therapy: a study of patients in the AIDS Therapy Evaluation in the Netherlands (ATHENA) Cohort. Clinical infectious diseases. 2010; 50 (2): 255-63.

[4] Deribew A, Deribe K, Reda AA, Tesfaye M, Hailmichael Y, Maja T, et al. Change in quality of life: a follow up study among patients with HIV infection with and without TB in Ethiopia. BMC public health. 2013; 13 (1): 408.

[5] Dewan R, GK I, Jiloha R. Assessment of Quality of Life among HIV Positive People Attending Tertiary Hospital of Delhi, India. J Commun Dis. 2009; 41 (2): 101-8.

[6] Mohamed N, Saddki N, Yusoff A, Jelani AM. Association among oral symptoms, oral health-related quality of life, and health-related quality of life in a sample of adults living with HIV/AIDS in Malaysia. BMC oral health. 2017; 17 (1): 119.

[7] Garai J. Gender and HIV/AIDS in Bangladesh: A review. Journal of Health and Social Sciences. 2016; 1 (3): 181-98.

[8] Mutabazi-Mwesigire D, Katamba A, Martin F, Seeley J, Wu AW. Factors that affect quality of life among people living with HIV attending an urban clinic in Uganda: a cohort study. PloS one. 2015; 10 (6): e0126810. 
[9] Gelibo T, Belachew T, Tilahun T. Predictors of sexual abstinence among Wolaita Sodo university students, South Ethiopia. Reproductive health. 2013; 10 (1): 18.

[10] HIV Related Estimates and Projections for Ethiopia-2017 March.

[11] MOFOLORUNSHO KC, NWANKWO EO, Babatunde T. Socio-Economic Factors Influencing the Quality of Life of People Living with HIV/AIDS in Kogi, Nigeria. Nature and Science. 2013; 11 (8): 33-9.

[12] Timilsina S, Regmi K. Assessing Quality of Life and Depression Among People Living With HIV/AIDS and TBHIV Coinfection in Kathmandu, Nepal. SAARC Journal of Tuberculosis, Lung Diseases and HIV/AIDS. 2015; 11 (2): 714.

[13] Annual report Benishangul Gumuz regional state health bureau 2016/2017.

[14] Annual HMIS report of Assossa general hospital 2016/2017.

[15] Alemu A, Yenealem A, Feleke A, Meseret S. Health Related Quality of Life Assessment and Associated Factors Among People on Highly Active Antiretroviral Therapy at Felege Hiwot Referral Hospital, Bahir Dar, North West Ethiopia. J AIDS Clin Res. 2013; 5 (272): 2.

[16] George S, Bergin C, Clarke S, Courtney G, Codd MB. Healthrelated quality of life and associated factors in people with HIV: an Irish cohort study. Health and quality of life outcomes. 2016; 14 (1): 115.

[17] Tesfay A, Gebremariam A, Gerbaba M, Abrha H. Gender differences in health related quality of life among people living with HIV on highly active antiretroviral therapy in Mekelle Town, Northern Ethiopia. BioMed research international. 2015; 2015.

[18] Safren SA, Hendriksen ES, Smeaton L, Celentano DD, Hosseinipour MC, Barnett R, et al. Quality of life among individuals with HIV starting antiretroviral therapy in diverse resource-limited areas of the world. AIDS and Behavior. 2012; 16 (2): 266-77.

[19] Haseli N, Esmaeelzadeh F, Ghahramani F, Alimohamadi Y, Hayati R, Mahboubi M. Health-related quality of life and its related factors in HIV+ patients referred to Shiraz Behavioral Counseling Center, Iran in 2012. Medical journal of the Islamic Republic of Iran. 2014; 2 8: 13.
[20] Deribew A, Tesfaye M, Hailmichael Y, Negussu N, Daba S, Wogi A, et al. Tuberculosis and HIV co-infection: its impact on quality of life. Health and quality of life outcomes. 2009; 7 (1): 105 .

[21] Mwesigire DM, Martin F, Seeley J, Katamba A. Relationship between CD4 count and quality of life over time among HIV patients in Uganda: a cohort study. Health and quality of life outcomes. 2015; 13 (1): 144.

[22] Razavi P, Hajifathalian K, Saeidi B, Esmaeeli Djavid G, Rasoulinejad M, Hajiabdolbaghi M, et al. Quality of life among persons with HIV/AIDS in Iran: internal reliability and validity of an international instrument and associated factors. AIDS research and treatment. 2012; 2012.

[23] Degroote S, Vogelaers DP, Vermeir P, Mariman A, De Rick A, Van Der Gucht B, et al. Socio-economic, behavioural, (neuro) psychological and clinical determinants of HRQoL in people living with HIV in Belgium: a pilot study. Journal of the International AIDS Society. 2013; 16 (1).

[24] Reis A, Guerra MP, Lencastre L. Treatment Adherence, Quality of Life and Clinical Variables in HIV/AIDS Infection. World. 2013; 3: 239-50.

[25] Nonenoy S. Health related quality of life among persons living with HIV/AIDS in 3 hospital in Thailand: Chulalongkorn University; 2009.

[26] Briongos Figuero L, Bachiller Luque P, Palacios Martin T, González Sagrado M, Eiros Bouza J. Assessment of factors influencing health-related quality of life in HIV-infected patients. HIV medicine. 2011; 12 (1): 22-30.

[27] Morineau G, Vun MC, Barennes H, Wolf RC, Song N, Prybylski D, et al. Survival and quality of life among HIVpositive people on antiretroviral therapy in Cambodia. AIDS patient care and STDs. 2009; 23 (8): 669-77.

[28] Mafirakureva N, Dzingirai B, Postma M, van Hulst M, Khoza S. Health-related quality of life in HIV/AIDS patients on antiretroviral therapy at a tertiary care facility in Zimbabwe. AIDS care. 2016; 28 (7): 904-12.

[29] Imam M, Karim M, Ferdous C, Akhter S. Health related quality of life among the people living with HIV. Bangladesh Medical Research Council Bulletin. 2011; 37 (1): 1-6. 